\title{
Management of Idiopathic Chronic Hydrocephalus of the Adult in Guinea: A Prospective Study in 16 Patients
}

\author{
Alpha Boubacar Bah ${ }^{*}$, Ibrahima Sory Souare ${ }^{2}$, Ibrahima Berete1, Seylan Diawara ${ }^{2}$, \\ Hugues Ghislain Atatla' ${ }^{1}$, Aboubacar M'mah Camara', Mamadou Khaira Bah ${ }^{1}$, Luc Kezely Beavogui ${ }^{1}$
}

${ }^{1}$ Service de Neurochirurgie, Hôpital National Donka, Conakry, Guinea

${ }^{2}$ Service de Neurochirurgie, Hôpital de l'Amitié Sino-Guinéenne de Kipé, Conakry, Guinea

Email: *cushing.bah@gmail.com

How to cite this paper: Bah, A.B., Souare, I.S., Berete, I., Diawara, S., Atatla, H.G., Camara, A.M., Bah, M.K. and Beavogui, L.K. (2021) Management of Idiopathic Chronic Hydrocephalus of the Adult in Guinea: A Prospective Study in 16 Patients. Open Journal of Modern Neurosurgery, 11, 272-280.

https://doi.org/10.4236/ojmn.2021.114032

Received: August 13, 2021

Accepted: October 24, 2021

Published: October 27, 2021

Copyright $\odot 2021$ by author(s) and Scientific Research Publishing Inc. This work is licensed under the Creative Commons Attribution International License (CC BY 4.0).

http://creativecommons.org/licenses/by/4.0/

(c) (i) Open Access

\begin{abstract}
Object: Incidence of Idiopathic chronic hydrocephalus of the adult (ICHA) is increasing in Guinea due to the aging of the population. The goal of this study was to describe its epidemiology, clinical presentation, and surgical outcome in a low-resource medical environment. Method: Sixteen patients operated for a probable ICHA were prospectively studied according to a uniform protocol from June 2019 to December 2020. On computerized tomography, all operated patients had a clinical triad of gait disturbance, incontinence, dementia associated with ventriculomegaly, and transependymal edema. In addition, all patients underwent a single lumbar tap, improved clinically, and were subsequently offered a shunt consisting of a simple catheter in $37.5 \%$ and a non-adjustable high-pressure valve in $62.5 \%$. Result: The mean age was $68.31 \pm 10.4$ (range 49 - 89). The sex ratio H/F was $1.67 / 1$. Clinically, the most frequent comorbidity was a combination of hypertension and diabetes in $56.5 \%$ of cases. The mean time to diagnosis was $8.31 \pm 2.75$ months (range 3 - 14). The immediate postoperative mortality was $12.5 \%$ from a status epilepticus and pulmonary sepsis. In addition, we observed 2 cases of chronic subdural hematoma (12.5\%) and 2 cases of shunt dysfunction $(12.5 \%)$ in the first three months. The functional outcome was good in $23 \%$ of patients at one month $(\mathrm{N}=13), 50 \%$ at three months $(\mathrm{N}=10)$, and $87.5 \%$ at six months $(\mathrm{N}=8)$. Conclusion: In carefully selected cases, the surgical outcome of ICHA in Guinea is comparable to high-income countries. Efforts need to be put in helping patients get covered with universal insurance and generally promote Neurosurgery in the country to improve the quality of care.
\end{abstract}




\section{Keywords}

Idiopathic Normal Pressure Hydrocephalus, Comorbidities, Ventriculoperitoneal Shunt, Lumbar Puncture

\section{Introduction}

Idiopathic Chronic Hydrocephalus of the Adult (ICHA) is a condition defined by an increase in the volume of brain ventricles resulting in a clinical syndrome characterized by gait disturbance, urinary incontinence, and cognitive decline and not caused by another central nervous system injury (infectious, vascular, or traumatic) [1]. Therefore, the initial observation of a normal Cerebrospinal fluid (CSF) pressure at lumbar puncture is no longer a criterion for affirming the diagnosis, which has helped move away from terminological discussions with normal pressure hydrocephalus in the French medical literature [2].

Appropriately identified, ICHA is a potentially reversible cause of dementia through permanent shunt placement. However, the clinical presentation being variable, the diagnosis and the management are perceived as a real challenge in Guinea, a low-income country with minimal medical resources, albeit an increasingly frequent cause of referral in neurosurgery.

This study aims to assess the extent of this disease in our practice and to describe the conditions, results, and problems of its management in Guinea.

\section{Patients and Methods}

This is a prospective study of patients operated on probable iCHA according to the international study guidelines for diagnosing and managing idiopathic Normal Pressure Hydrocephalus [3] from June 2019 to December 2020. It was carried out at the CHU of Donka, Guinea, a country of 13 million population in which Neurosurgery is in its earlier phase of development. The whole economic burden of medico-surgical care is entirely on each patient.

Patients with a history of stroke, neurotrauma, or brain tumor were excluded. All the patients underwent a brain scan and a depletive lumbar puncture. They were kept in hospital for 12 hours to evaluate the motor and executive functions by the up-and-go test in patients who could stand. This test asks the patient to stand up, walk 3 meters before returning to his starting position in less than 10 seconds [4]. Patients were then sent home, and families were asked to record any global change in cognitive status and motor disorders. In case of any clinical improvement, the selected patients were subsequently admitted for ventriculoperitoneal shunt either with a single catheter ligated distally with lateral fenestrations or with non-adjustable high-pressure valves. After the surgery, each patient was asked to lie flat for two days, then authorized to stand progressively as tolerated. Patients were seen at 1-month intervals for the first three months for clinical signs of hypodrainage and chronic subdural hematoma treated when appro- 
priate by temporary distal catheter ligation and hematoma evacuation.

The parameters collected for the study were age, gender, time from admission to first symptoms, presence of comorbidities, clinical data before and after depletive lumbar puncture, Evans's index, and presence of transependymal edema in the scanner, shunt device used, immediate postoperative complications and during follow-up. The overall clinical course after the procedure was evaluated at 1,3 and 6 months postoperative according to the classification of Bret and Chazal [5]. Thus, the functional status was classified as good in case of a return to the previous state or autonomy for the acts of daily life (defined as the primary success variable); average results with a real but incomplete benefit that does not allow for independent living; and poor results for cases of stability or aggravation. Death represents the final grade of this classification.

Qualitative variables were expressed in terms of numbers and percentages, and quantitative data in terms of averages with their respective standard deviation sometimes presented in tabular form. The Excel software for Windows Office 2018 has been used.

\section{Results}

After applying our inclusion and exclusion criteria, 16 files were selected for analysis, i.e., $4 \%$ of patients operated in the department of neurosurgery during the study period. Extreme ages ranged from 49 - 89 years with an average of $68.31 \pm 10.4$ years and a peak frequency in the $61-70$ age group (Table 1 ). The predominance was male with a sex ratio of H/F of 1.67/1. Clinically, 15 out of 16 patients had at least one comorbidity, the most frequent of which was the combination of high blood pressure and diabetes in $56.5 \%$ of cases (Table 2).

Table 1. Patients distribution according to age groups.

\begin{tabular}{ccc}
\hline Age (years) & Number & Percentage \\
\hline $40-50$ & 1 & 6.25 \\
$51-60$ & 2 & 12.50 \\
$61-70$ & 6 & 37.50 \\
$71-80$ & 5 & 31.25 \\
$81-90$ & 2 & 12.50 \\
Total & 16 & 100.00 \\
\hline
\end{tabular}

Table 2. Patients distribution according to comorbidities.

\begin{tabular}{ccc}
\hline Comorbidity & Number & Percentage \\
\hline Hypertension (HTN) & 2 & 12.5 \\
Diabetes (DM) & 1 & 6.25 \\
HTN + DM & 9 & 56.5 \\
Benign prostatic Hyperplasia (BPH) & 4 & 25.00 \\
Lumbar Canal Stenosis (LCS) & 1 & 6.25 \\
\hline
\end{tabular}


The mean time to diagnosis of our patients was $8.31 \pm 2.75$ months with extremes of 3 - 14 months. Adam Hakim's symptomatologic triad was complete in all patients. Two patients (12.5\%) were bedridden with an impossible sitting position; 5 patients $(31.2 \%)$ could sit with armrests, and nine patients (56.2\%) had apraxia for walking. All patients experienced significant psychomotor retardation with apathy and temporospatial disorientation, and 4 of these patients developed akinetic mutism (25\%). Thirteen patients $(81.25 \%)$ had urinary incontinence associated with fecal incontinence in 3 of them. Five patients $(31.5 \%)$ had a urinary urgency. The non-contrast head CT showed ventricular dilation and transependymal edema in all our patients with an average Evans index of $0.36 \pm 0.047$ and extremes of $0.28-0.43$. The depletive lumbar puncture improved motor execution on the up-and-go test in 10 cases (62.5\%) and a subjective functional improvement perceived by the family at home in all cases. Six patients (37.5\%) underwent surgery using a single catheter without a valve, and ten patients received a high-pressure valve (62.5\%).

The postoperative course was marked in the first three weeks by 1 case of status epilepticus leading to death and one case of pulmonary sepsis. We observed 1 case of subdural hematoma at one month, who refused to be treated and subsequently lost to follow up; and a second one at three months, treated with temporary catheter ligation and burr-hole drainage of the hematoma. The other postoperative complications diagnosed in the follow-up were two cases of valve dysfunction; the first at one month refused the treatment, and was transferred abroad by the family. The second one at three months benefited from a shunt revision with a non-adjustable medium pressure valve. The functional success rate (good result) was $23 \%$ at 1 month $(\mathrm{n}=13), 50 \%$ at 3 months $(\mathrm{N}=$ $10)$, and $87.5 \%$ at 6 months $(\mathrm{N}=8)$ (Figure 1$)$.

\section{Discussion}

ICHA is a good representative model of the long-time dogma that neurosurgery is too expansive in low resource settings and is perceived this way by hospital managers, doctors of other specialties, patients, and the public in Guinea. Some

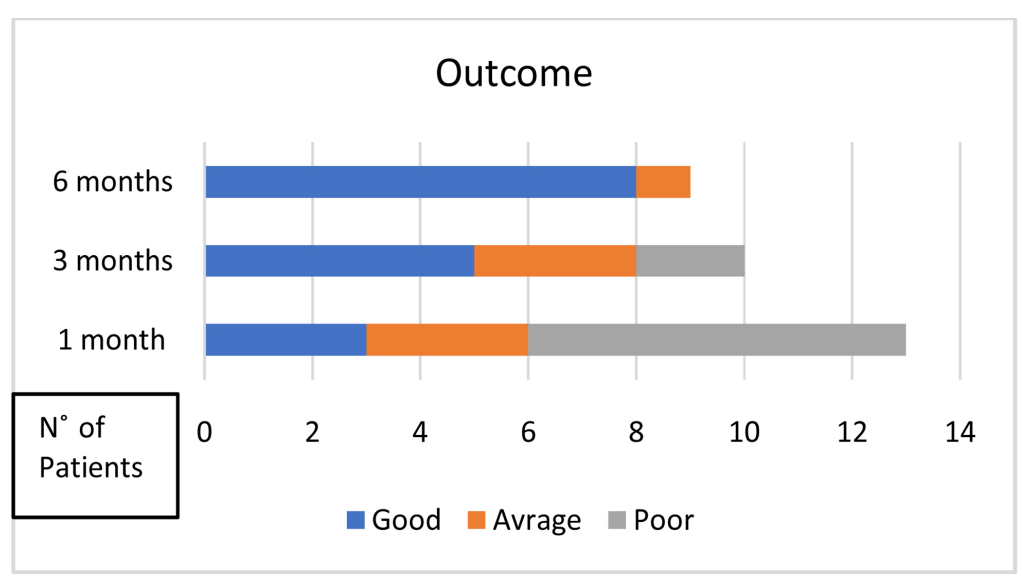

Figure 1. Functional outcomes according to the Bret and Chazal classification. 
evidence suggests that surgical treatment of hydrocephalus is cost-effective in most high-income countries [6] [7].

Still, in a setting where patients and families are responsible for the medical and pharmaceutical bills, the standard unpredictability of shunt surgical results and complications makes it challenging to integrate neurosurgical diseases like ICHA in the national public health network.

The aging population and the epidemiological transition are causing an exponential increase in the incidence of ICHA and should lead us to pay particular attention to it.

Life expectancy in the Republic of Guinea has increased from 35 years in 1965 to 61 years in 2019 [8]. This aging population has led to an increase in the number of neurological visits for dementia syndromes associated with significant motor disorders and urinary incontinence transiently reversed by a depletive lumbar puncture, hence the suspicion of ICHA. The average age of 67.5 years and the peak incidence in the 6th decade found in our study are slightly younger than the literature [9]. Prevalence was estimated to be $1.30 \%$, and its incidence was $0.12 \%$ in a literature review conducted in 2015 [9]. In Africa, the prevalence was mainly determined in neurosurgery services. It averaged 2.5 cases per year in Dakar between 1997 and 2003 [10]. Fourcases were reported by Magadji et al. in 2015 in Yaoundé, Cameroun [11]. In our study, 16 cases were collected over 18 months. These figures, under-estimated mainly, are difficult to compare because of their temporality (the Dakar study dates back more than 15 years) and the significant variability in the diagnostic criteria and methodologies used. They do, however, reflect the growing interest in this condition in the continent's neurosurgery services.

Although the mechanism of occurrence of ICHA is still poorly understood, the most described physiopathological models are vascular: ischemia of the white peri-ependymal substance; reduction of venous compliance; redistribution of LCS pulsatile streams [12]. These assumptions are reinforced by the high frequency of vascular comorbidities in patients with probable ICHA: $56 \%$ of our patients had hypertension/diabetes, in line with the literature [13].

Gait disturbances are known to appear early in the course of the disease [14]. For a long time, they were the unique symptom in one of our patients, initially diagnosed with lumbar canal stenosis and operated on without improvement. They have subsequently evolved in $43.7 \%$ of our patients into an overall motor regression as described in 2005 by Chazal "in the reverse direction of the early childhood motor milestone chronology" [15]. Cognitive impairment subsequently began as a personality change, mood disorder, and then evolved into advanced psychomotor retardation in all cases and akinetic mutism in $37.5 \%$ of cases.

The nature of this cognitive profile and its evolution appearing clearly after motor disorders have been described as favoring the suspicion of ICHA over Alzheimer's Disease [16]. At the most severe stages of cognitive decline, as is the 
case for our patients at diagnosis, this clinical distinction is more difficult to achieve [16]. Urinary disorders have evolved concomitantly with gait disorders in $31.2 \%$ of cases and are well described in the literature [17]. Nocturnal urinary urgency has been a source of misdiagnosis in three patients who underwent surgery for benign prostatic hypertrophy before being referred to neurosurgery for incontinence and cognitive impairment.

The clinical originality of our series compared to the literature lies in the completeness of Adam Hakim's triad in all our patients (this was one of the inclusion criteria we chose) and the severity of the clinical signs at the time of diagnosis. It reflects the long delay in diagnosis that we have found and the lack of knowledge of this pathology in the national care pathways.

Coupling the search for periventricular lucency and the measure of the Evans index on non-contrast head CT scan allows for quantification of ventricular dilatation, differentiating it from simple cortical-subcortical atrophy and also help to eliminate other apparent causes of secondary hydrocephalus [18], in the setting of the severe clinical profile of patients in our series. Unfortunately, brain MRIs are not affordable, and the contemporary sophistication in the volumetric and dynamic sequences for the diagnosis of ICHA [19] are not available and not necessary in Guinea, in our opinion.

Depletive lumbar puncture aims to show a transient clinical improvement (mainly on motor disorders) to be measured in the first 24 hours to reduce the number of false negatives [20], and whose positive predictive value would be $90 \%-100 \%$ improvement after shunting. There are many tests to assess this improvement in the literature [21], and none were applied to our context, given the severity of the disorders. The only test used was an untimed version of the up-and-go test and the overall subjective impression of close family caregivers. All patients experienced a marked improvement in motor and cognitive disorders after depletive lumbar puncture. The added benefit of leaving this subjective assessment to the family was that they would adhere to the surgical indication in a context where neurosurgery is still an unknown discipline in the general population.

The curative treatment is surgical and is based on the internal derivation of the LCS to a site of extracranial resorption. In sub-Saharan Africa and our study, a ventriculoperitoneal derivation is the most used technique [10] [11], as in most Western studies [22]. It is the type of valve used that differs according to the socio-economic level of the study population. Adjustable valves make it possible to compensate for the complications due to initial low or high pressure [23]. However, the flow-regulating valves, non-externally adjustable valves, may have their place in a social context in which the postoperative follow-up of the patient is uncertain or even impossible [24]. In extreme conditions like ours, a single shunt catheter was used without a valve in 37.5 percent of cases. We used non-adjustable Chhabra valves in all others, mainly tested on pediatric series [25]. According to Warf and Coll, they have a very accessible cost and would not show any significant difference in terms of results and complications compared 
with the standard adjustable valves [25]. Despite the difference in materials used, the rates of complications of our study are comparable to those of the literature [26] and relate mainly to postoperative infection $(0.06 \%$ of the cases in our study), chronic subdural hematomas (12.5\% of the cases) and valve dysfunctions (12.5\% of the cases). The overall functional result we assessed at one month, three months, and six months also appear to be in line with that of the literature [27], with a more significant improvement between 3 and 5 months [28].

These comparisons must take into account many limitations of our research: Our patients were not followed beyond six months, and only the patients with good and average results showed up at the 6-month follow up evaluation; one patient with a subdural hematoma and another with a valve dysfunction refused the treatment offered to them, perceiving the occurrence of complications as related to poor quality of care; We didn't precisely measure the opening pressure of the CSF during the depletive lumbar puncture; no brain scan was performed during follow-up, except for cases of complications confirmed by clinical examination; among the clinical signs, only motor symptoms were objectively measurable and improved correlating with the satisfaction of close caregivers, who were more reluctant to complete micturition schedules and generally discuss details of urinary continence and cognitive impairment of patients during follow-up.

\section{Conclusion}

A ventriculoperitoneal shunt is a safe and effective treatment of probable ICHA in selected cases. The functional outcome and complications rates appear to be equivalent in low-income countries compared to high-income countries. But the perception of the quality of neurosurgical care in the general public is altered by the fact that neurosurgery is still new in Guinea, and patients don't have the financial resources to afford more appropriate materials and further treatment of shunt complications. The lack of universal health coverage in Guinea is a major obstacle in the development of Neurosurgery in the country.

\section{Conflicts of Interest}

The authors declare no conflicts of interest regarding the publication of this paper.

\section{References}

[1] Bret, P., Ricci, A.-C., Guyotat, J., Chazal, J. and Lemaire, J.-J. (2004) Hydrocéphalie chronique de l'adulte (hydrocéphalie à pression normale). EMC-Neurologie, 1, 1-11. https://doi.org/10.1016/S0246-0378(02)00119-7

[2] Bret, P., Ricci, A.-C., Guyotat, J. and Chazal, J. (2002) Is Normal Pressure Hydrocephalus a Valid Concept in 2002? A Reappraisal in Five Questions and Proposal for a New Designation of the Syndrome as "Chronic Hydrocephalus". Journal of Neurology, Neurosurgery and Psychiatry, 73, 9-12. https://doi.org/10.1136/jnnp.73.1.9 
[3] Etsuro, M., Masatsune, I., Takeo, K., et al. (2012) Guidelines for Management of Idiopathic Normal Pressure Hydrocephalus: Second Edition. Neurologia Medico-Chirurgica (Tokyo), 52, 775-809. https://doi.org/10.2176/nmc.52.775

[4] Podsiadlo, D. and Richardson, S. (1991) The Timed "Up \& Go": A Test of Basic Functional Mobility for Frail Elderly Persons. Journal of the American Geriatrics Society, 9, 142-148. https://doi.org/10.1111/j.1532-5415.1991.tb01616.x

[5] Bret, P. and Chazal, J. (1995) Hydrocéphalie chronique de l'adulte (hydrocéphalie à pression normale). Editions techniques. Encycl. Med. Chir. (Paris-France). Neurologie. 17-154-B-10. 8 p.

[6] Klinge, P., Marmarou, A., Bergsneider, M., Relkin, N. and Black, P.M. (2005) Outcome of Shunting in Idiopathic Normal-Pressure Hydrocephalus and the Value of Outcome Assessment in Shunted Patients. Neurosurgery, 57, S40-S52. https://doi.org/10.1227/01.NEU.0000168187.01077.2F

[7] Shaw, R., Everingham, E., Mahant, N., Jacobson, E. and Owler, B. (2016) Clinical Outcomes in the Surgical Treatment of Idiopathic Normal Pressure Hydrocephalus. Journal of Clinical Neuroscience, 29, 81-86. https://doi.org/10.1016/j.jocn.2015.10.044

[8] Espérance de vie à la naissance, total (années)—Guinea. https://donnees.banquemondiale.org/indicator/SP.DYN.LE00.IN?locations=GN

[9] Martín-Láez, R., Caballero-Arzapalo, H., López-Menéndez, L.Á., Arango-Lasprilla, J.C. and Vázquez-Barquero, A. (2015) Epidemiology of Idiopathic Normal Pressure Hydrocephalus: A Systematic Review of the Literature. World Neurosurgery, 84, 2002-2009. https://doi.org/10.1016/j.wneu.2015.07.005

[10] Code, B.M., Adil, H., Youssoupha, S., Ndaraw, N., et al. (2007) L'hydrocephalie chronique de l'adulte: A propos de 15 cas. African Journal of Neurological Sciences, 26, 38-41. https://doi.org/10.4314/ajns.v26i2.7594

[11] Magadji, J.P., Sini, V., Bello, F., Jemea, B., et al. (2015) Hydrocephalie Chronique: A propos de 4 cas. Revue Africaine de Chirurgie et Spécialités, No. 1, 24-28.

[12] Bateman, G.A. (2008) The Physiopathology of Idiopathic Normal Pressure Hydrocephalus: Cerebral Ischemia or Altered Venous Hemodynamics. American Journal of Neuroradiology, 29, 198-203. https://doi.org/10.3174/ajnr.A0739

[13] Eide, P.K. and Pripp, A.H. (2014) Increased Prevalence of Cardiovascular Disease in Idiopathic Normal Pressure Hydrocephalus Patients Compared to a Population-Based Cohort from the HUNT3 Survey. Fluids and Barriers of the CNS, 11, 19. https://doi.org/10.1186/2045-8118-11-19

[14] Kuba, H., Inamura, T., Ikezaki, K., Inoha, S., Nakamizo, A., Shono, T., et al. (2002) Gait Disturbance in Patients with Low Pressure Hydrocephalus. Journal of Clinical Neuroscience, 9, 33-36. https://doi.org/10.1054/jocn.2001.1010

[15] Chazal, J. (2005) L'hydrocephalie chronique de l'adulte: Où en est le concept en 2005. Neurochirurgie, 51, 38-40. https://doi.org/10.1016/S0028-3770(05)83419-8

[16] Ogino, A., et al. (2006) Cognitive Impairment in Patients with Idiopathic Normal Pressure Hydrocephalus. Dementia and Geriatric Cognitive Disorders, 21, 113-119. https://doi.org/10.1159/000090510

[17] Bey, E., Nicot, B., Casez, O. and Normand, L.L. (2016) Troubles vesico-sphincteriens dans l'hydrocephalie a pression normale: Revue de la littérature. Progrèsen Urologie, 26, 1191-1199. https://doi.org/10.1016/j.purol.2016.10.004

[18] Miskin, N., Patel, H., Franceschi, A.M., Ades-Aron, B., Le, A., Damadian, B.E., et al. (2017) Diagnosis of Normal-Pressure Hydrocephalus: Use of Traditional Measures 
in the Era of Volumetric MR Imaging. Radiology, 285, 197-205. https://doi.org/10.1148/radiol.2017161216

[19] Al-Zain, F.T., Rademacher, G., Meier, U., Mutze, S. and Lemcke, J. (2008) The Role of Cerebrospinal Fluid Flow Study Using Phase Contrast MR Imaging in Diagnosing Idiopathic Normal Pressure Hydrocephalus. Acta Neurochirurgica Supplement, 102, 119-123. https://doi.org/10.1007/978-3-211-85578-2 24

[20] Virhammar, J., Cesarini, K.G. and Laurell, K. (2012) The CSF Tap Test in Normal Pressure Hydrocephalus: Evaluation Time, Reliability and the Influence of Pain. European Journal of Neurology, 19, 271-276. https://doi.org/10.1111/j.1468-1331.2011.03486.x

[21] Hellström, P., Edsbagge, M., Blomsterwall, E., Archer, T., Tisell, M., Tullberg, M., et al. (2008) Neuropsychological Effects of Shunt Treatment in Idiopathic Normal Pressure Hydrocephalus. Neurosurgery, 63, 527-536.

https://doi.org/10.1227/01.NEU.0000325258.16934.BB

[22] Mongin, M., Hommet, C. and Mondon, K. (2015) Hydrocéphalie à pression normale $\int$ mise au point et aspects pratiques. La Revue de Médecine Interne, 36, 825-833. https://doi.org/10.1016/j.revmed.2015.08.001

[23] Richards, H., Seeley, H. and Pickard, J. (2007) Are Adjustable Valves Effective? Data from the UK Shunt Registry. Fluids and Barriers of the CNS, 4, S30. https://doi.org/10.1186/1743-8454-4-S1-S30

[24] Fritsch, M.J., Kehler, U. and Meier, U. (2014) Normal Pressure Hydrocephalus. Pathophysiology, Diagnosis and Treatment. Thieme.

https://doi.org/10.1055/b-0034-98124

[25] Benjamin, W.C. (2005) Comparison of 1-Year Outcomes for the Chhabra and Codman Hakim Micro Precision Shunt Systems in Uganda. A Prospective Study in 195 Children. Journal of Neurosurgery. Pediatrics, 102, 358-362. https://doi.org/10.3171/ped.2005.102.4.0358

[26] Aschoff, A., Kremer, P., Benesch, C., Fruh, K., Klank, A. and Kunze, S. (1995) Overdrainage and Shunt Technology. A Critical Comparison of Programmable, Hydrostatic and Variable-Resistance Valves and Flow Reducing Devices. Child s Nervous System, 11, 193-202. https://doi.org/10.1007/BF00277653

[27] Haroon, K., Taher, T., Rahman, M., Mahmud, K., Paul, S., Hossain, S., et al. (2016) Immediate Postoperative Outcome of Ventriculoperitoneal Shunt Surgery in NPH Patients. Bangladesh Journal of Neurosurgery, 6, 8-11.

[28] Tisell, M., Hellström, P., Ahl-Börjesson, G., Barrows, G., Blomsterwall, E., Tullberg, M., et al. (2006) Long-Term Outcome in 109 Adult Patients Operated on for Hydrocephalus. British Journal of Neurosurgery, 20, 214-221.

https://doi.org/10.1080/02688690600852324 